\section{Broken necks in passengers in London taxi accidents}

Travelling by London taxi cab is considered to be safe. We present two cases of odontoid fracture as a result of taxi accidents.

\section{Case histories}

Case 1-A 62 year old woman was a passenger in the back of a London taxi which collided with another car. She was thrown forward and hit her head on the partition between the passengers' and driver's compartments. She immediately experienced severe neck pain aggravated by movement. Examination showed occipital bruising, torticollis, and spasm of the neck muscles. No pharyngeal swelling or abnormal neurological signs were detected. Cervical radiographs showed an undisplaced fracture at the base of the odontoid peg. She was placed in a Plastazote collar, which eased her pain. The fracture healed spontaneously.

Case 2-A 55 year old man was in the back of a cab when it was in a collision. He struck the left side of his head on the partition. Within two hours he developed severe neck pain. Examination showed torticollis, spasm of the neck muscles, but no abnormal neurological signs. He was placed in a conventional soft collar. His torticollis worsened over the next week and he developed right arm weakness, inversion of the right supinator reflex, and extensor plantar responses. Computed tomography of the craniocervical junction confirmed the suspicion of an undisplaced fracture at the base of the odontoid peg (figure). A Plastazote collar relieved his pain and after two months he was fully recovered.

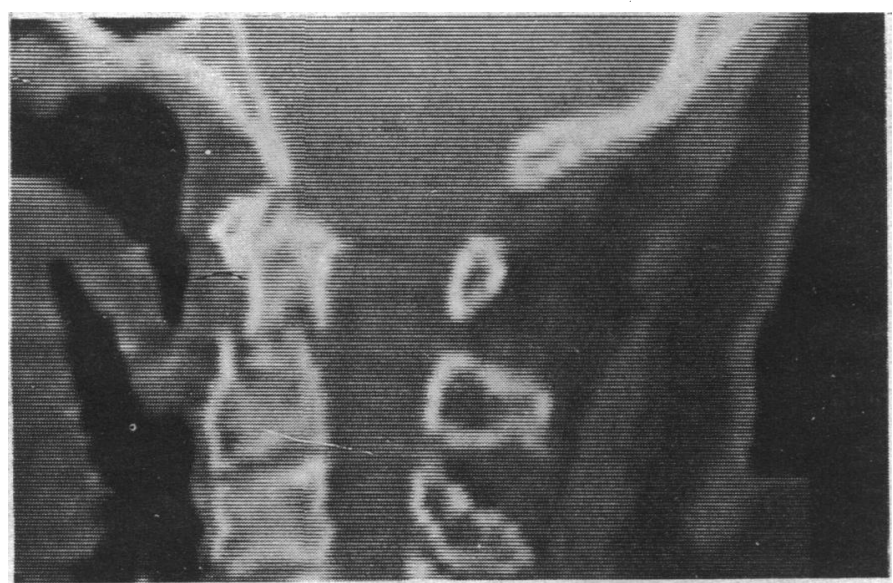

Minimally displaced odontoid fracture (case 2) shown by computed tomography.

\section{Comment}

In 1920 Jefferson reported 46 cases of fracture of the atlas and described the mechanism whereby a blow on the vertex could be transmitted to the atlas and disrupt the ring of the atlas (the Jefferson fracture) or fracture the odontoid. ${ }^{1}$ A victim of a fractured odontoid survives only when the transverse ligament is intact and the peg is not displaced into the medulla.

Such fractures are difficult to diagnose, but neck pain, torticollis, and limitation of neck movements should alert the clinician to the possibility of an odontoid fracture. ${ }^{2}$ The area is difficult to visualise radiologically, open mouth views and tomography being essential. Undoubtedly the best method of diagnosis is a fourth generation computed tomogram. ${ }^{3}$ Treatment traditionally necessitates either surgery with internal fixation and fusion or external fixation with halo pelvic stabilisation. ${ }^{4}$ In our cases we showed that the fractures were stable and were able to treat them using a custom made Plastazote collar, which led to resolution of symptoms and torticollis in about six weeks.

The occurrence of these fractures in low speed collisions in London taxis is disturbing. The "black cab" is world famous, being of saloon design with a high roof and seating for up to four people in the back. Between driver and passengers there is a complete partition, the lower half metal, the upper half glass. While this arrangement is comfortable and practical, the combination of a high roomy passenger cab with a solid partition at the front makes it likely a passenger will be thrown forward on to the partition and suffer head or neck injuries in a collision. The wearing of rear seat belts would prevent this.

A disturbing feature is that no records are available on the number of taxi accidents. Inquiries with the Metropolitan Police, the Hackney Carriage Licensing Authority, and the London Taxi Drivers' Association indicated that taxi accidents are included with general motor vehicle accidents for statistical purposes and that there is no way of finding out the number of taxi accidents or the number of passengers injured per year. For a public service carrying large numbers of passengers this is surprising and perhaps worthy of change.

1 Jefferson G. Fracture of the atlas vertebra. Report of four cases and a review of those previously recorded. Br $\mathcal{Y}$ Surg 1920;7:407-11.

2 Richards P. Stable fracture of the atlas and axis in children. 7 Neurol Neurosurg Psychiatry 1984;47:781-3.

3 Keene GCR, Hone MR, Sage MR. Atlas fracture demonstration using computerised tomography. J Bone Joint Surg 1978;60:1106-7.

4 Hadley MN, Browner C, Sonntag VKH. Axis fracture: a comprehensive review of managemen and treatment in 107 cases. Neurosurgery 1985;17:281-90.

(Accepted 27 February 1986)

National Hospitals for Nervous Diseases, Maida Vale, London W9 1TL

PG RICHARDS, FRCS, senior registrar in neurosurgery

H A CROCKARD, FRCS, consultant neurosurgeon

\section{Deficient urinary fibrinolysis in renal stone disease}

In much the same way that circulating fibrinolysis prevents the formation of thrombi in the vascular system, urinary fibrinolytic activity helps to degrade those macromolecules ${ }^{1}$ that are essential for the genesis of renal calculi. Urinary fibrinolytic activity was measured in 188 patients with undoubted urolithiasis and compared with values in an equal number of controls matched for sex, age, and geographical location.

\section{Patients, methods, and results}

Each patient was randomly matched through his or her family practitioner committee. Two urine samples were collected from each of the 188 patients with stones and one specimen from each of their controls. The urinary fibrinolytic activity was measured by the unheated fibrin plate method, ${ }^{3}$ and so the urokinase content (Ploug units) was determined. Urinary creatinine concentration was measured, and, since the urokinase excretion is constant throughout 24 hours and from day to day, ${ }^{4}$ urinary fibrinolytic activity was expressed in Ploug units per $\mathrm{mg}$ of creatinine.

Preliminary assessment of sample size requirements suggested that 100 cases would give $90 \%$ power to detect a difference of 2.7 Ploug units $/ \mathrm{mg}$ creatinine between cases and controls ( $5 \%$ test, not log scale).

Among the patients there were 129 men; one third of the patients (63) were aged 45 to 54 , with 53 in the youngest group (21 to 45 ). Age matching was to the same year of birth for 120 cases and to within two years for 179 .

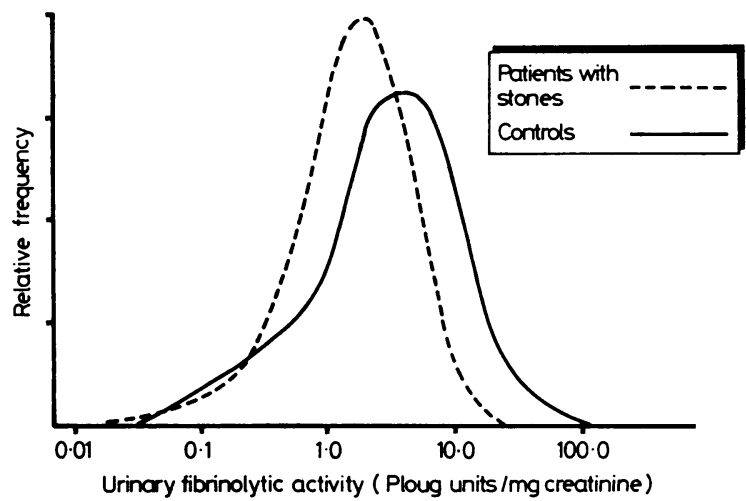

Frequency curves of urinary fibrinolysis activity $\left(\log _{e}\right)$ for stone patients and controls.

The distribution of urinary fibrinolytic activity was highly skewed, so the statistical analysis used log values (see figure). The control readings suggested a slight reduction in urinary fibrinolytic activity with age but no differences between the sexes. The controls' median value was 3.42 Ploug units/mg creatinine with a lower quartile of $1 \cdot 50$, an upper quartile of $7 \cdot 22$, and a range of 0.06 to $45 \cdot 3$. On the logarithmic scale the mean for controls was 1.01 ( 2.75 Ploug units/mg) with standard deviation $1 \cdot 27$

The median value for the 188 patients with stones was 1.63 Ploug units/mg creatinine, with a lower quartile of $0 \cdot 86$, an upper quartile of $3 \cdot 16$, and a range of 0.03 to $17 \cdot 4$. On the logarithmic scale the mean was $0.41(1.50$ Ploug units $/ \mathrm{mg})$ with standard deviation 1.03 . 
A matched pair $t$ test gave a mean difference of 0.60 (standard error $0 \cdot 12,95 \%$ confidence interval 0.37 to $0.83, t=5.11, \mathrm{df}=187, \mathrm{p}<0.001$; the urinary fibrinolytic activity scale multiplicative factor was thus $1.83,95 \%$ confidence interval 1.45 to $2 \cdot 30$ ). This was a strongly statistically significant result, as expected, since 125 patients with stones had lower urinary fibrinolytic activities than their controls.

\section{Comment}

The crystalloids in the urine found in stones have received much attention, but there is little understanding of the factors controlling the behaviour of the organic macromolecules and their contribution to the genesis of urinary calculi. At least two thirds of the macromolecules in the urine of normal individuals have a molecular weight of less than 50000 , whereas in patients with stones all macromolecules are larger than this. ${ }^{5}$ It is therefore suggested that urokinase splits the larger aggregates into lesser macromolecules and this results in an increase of their surface area, which in turn results in an increase in the amount of crystalloids adsorbed on to these surfaces. A lowering of urinary fibrinolytic activity will result in a proportionate increase in the number of larger aggregates, and so there will be more free crystalloids in solution for precipitation, thus contributing to concrement formation.

Our study has shown that two thirds of stone formers have lower urinary fibrinolytic activity than matched controls, that this is an important factor in urolithiasis, and that it would be logical to raise the value of urinary fibrinolytic activity to physiological levels in an attempt to prevent the formation of further stones in these patients.

This work was funded by the Wessex RHA Research Committee, and we thank Mrs Janet Jory and Ms Shirley Simmonds for their help.

1 Charlton CAC. The relation of urolithiasis to urinary fibrinolytic activity. In: Hodgkinson A, Nordin BEC, eds. Renal stone research symposium. London: J and A Churchill Ltd, 1969:191-7. 2 Boyce WH, King JS. Crystal-matrix interrelations in calculi. $\mathcal{J}$ Urol 1959;81:351-65.

3 Astrup T, Mullertz S. The fibrin plate method for estimating fibrinolytic activity. Arch Biochem Biophys 1952;40:346-51.

4 Boomgard J, Vreeken J, Bleynberg A, Deggellerg K. Studies in urokinase. Some physiological considerations concerning normal urokinase excretion. Clin Chim Acta 1966;13:484-90.

5 Drach GW, Kraljevich Z, Randolph AD. Effects of high molecular weight urinary macromolecules on crystallization of calcium oxalate dihydrate. $\mathcal{F}$ Urol 1982;127:805-10.

(Accepted 28 February 1986)

\section{Royal United Hospital, Bath BA1 3NG}

CLIVE A C CHARLTON, MS, FRCS, consultant urologist

MRC Environmental Epidemiology Unit, Southampton

CLIVE OSMOND, MA, PHD, statistician

\section{Aneurysm presenting as a breast mass}

Clinical teaching dictates that an aneurysm must be included in the differential diagnosis of a mass. This is rarely thought of, however, when breast lumps are examined. We report on a patient with an aneurysm presenting as a breast mass, probably caused by the spontaneous rupture of a vessel during a period of acute hypertension.

\section{Case report}

A 57 year old hypertensive woman with quiescent ulcerative colitis suffered an exacerbation of her hypertension, manifested by severe headaches, palpitations, and tremor. Her sitting blood pressure was $185 / 115 \mathrm{~mm} \mathrm{Hg}$, and her antihypertensive treatment was increased to metoprolol $100 \mathrm{mg}$ six hourly and chlorthalidone $50 \mathrm{mg}$ daily. In addition, she was receiving sulphasalazine $1 \mathrm{~g} 12$ hourly to control her colitis. During this hypertensive episode she was woken one night by a sudden, severe pain in her right breast, and the next morning bruising was noticed over the lower half of the breast. There was no history of trauma to that breast.

When she was referred to hospital two weeks later a $3 \mathrm{~cm}$ smooth, mobile mass was palpated in the upper outer quadrant of the right breast; bruising was still apparent in the lower half of the breast. Bloodstained fluid was aspirated from the mass and both ultrasound and mammography showed a cystic lesion in the affected area.

Before excision biopsy thoracic examination by the anaesthetic senior house officer showed a loud murmur originating from the breast mass. The murmur could be stopped by pressure, medial to the mass, over the right second rib. Angiography through the right subclavian artery showed an aneurysmal arteriovenous fistula arising from the right anterior second intercostal artery (figure).

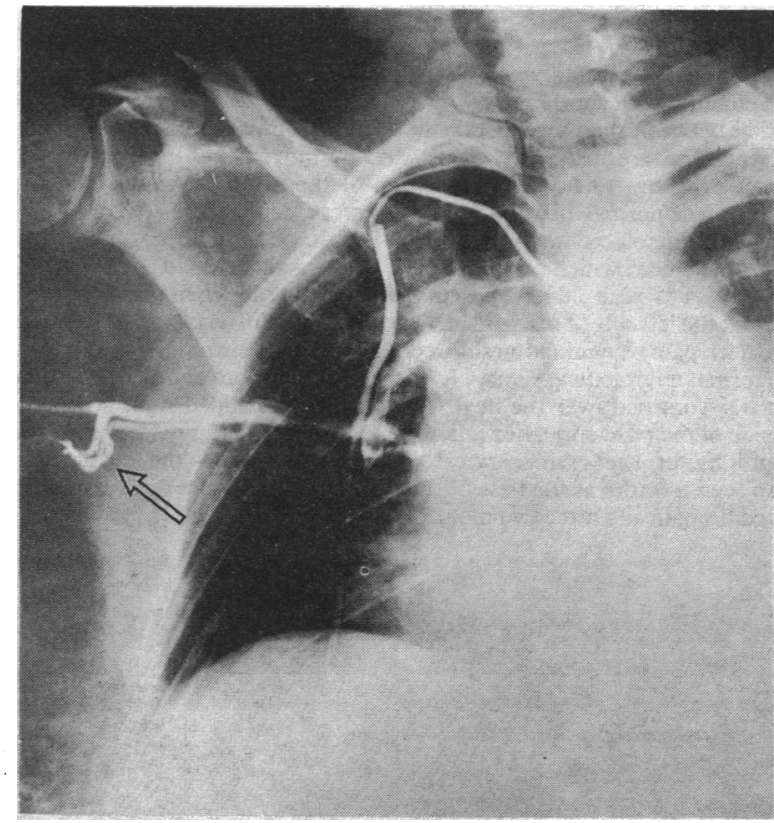

Radiograph of right subclavian angiogram, showing the aneurysm (open arrow) and its feeding artery and draining vein.

The aneurysm was excised with ligation of the feeding artery and draining vein Histological examination showed a false aneurysm, filled with a blood clot, in continuity with the feeding artery. No focal features were present to suggest atherosclerotic degeneration, trauma, vasculitis, or medial degeneration.

\section{Comment}

Aneurysms of the intercostal arteries are rare but may occur after sudden trauma. ${ }^{1}$ The aetiology of this aneurysm remains obscure, as there were no salient histological features to suggest its origin. In the absence of any history of trauma we believe that the most likely cause was the spontaneous rupture of a vessel during a period of acute hypertension, resulting in a false aneurysm with an arteriovenous communication.

Rupture of arteries in the acute hypertensive state is well described in association with intracerebral vessels, ${ }^{2}$ the circle of Willis, ${ }^{3}$ and the aorta, ${ }^{4}$ but to our knowledge there are no reports concerning this condition in the breast.

We thank Dr Anne Davies, anaesthetic senior house officer, for auscultating the breast mass and bringing to light this diagnosis. We thank Dr E W L Fletcher for performing the angiography and Mrs Brenda Carter for typing the manuscript.

1 McLaughlin JS, Linberg EJ, Lanzi JG, et al. Traumatic intercostal arteriovenous fistula: case report. Ann Surg 1965;161:218-20.

2 Porter KA. Hypertension. In: Symmers WStC, ed. Systemic pathology. 2nd ed. Edinburgh Churchill Livingstone, 1976.

3 Yates PO. Vascular disease of the central nervous system. In: Blackwood W, Corsellis JAN, eds. Greenfield's neuropathology. 3rd ed. Chicago: Year Book Medical Publishers, 1976.

4 Fox S, Pierce WS, Waldhausen JA. Acute hypertension: its significance in traumatic aortic rupture. I Thorac Cardiovasc Surg 1979;77:622-5.

(Accepted 10 March 1986)

Nuffield Department of Surgery, John Radcliffe Hospital, Oxford OX3 9DU

T C B DEHN, MS, FRCs, clinical lecturer

E C G LEE, MCH, FRCs, consultant surgeon (Mr Lee died in January 1986) 